\title{
Introduction to the special issue
}

\author{
Brian A. Anderson ${ }^{1}$
}

Published online: 25 August 2016

(C) The Psychonomic Society, Inc. 2016

Like many young scientists, I first encountered Steven Yantis through reading his papers. My research had led me to the classical stimulus-driven vs. goal-directed control of attention debate. In familiarizing myself with this literature, I was struck by how frequently the name Yantis would be invoked regardless of which position the author was defending. Either Steven Yantis was a very conflicted individual, or there was something deeply integrative about his work that gave it exceptionally broad appeal. It took me only a couple of papers before I realized which was the case, and who I wanted to be my $\mathrm{PhD}$ advisor.

Many readers of Attention, Perception, and Psychophysics remember Steven Yantis for his sharp intellect. His rare combination of experimental elegance and theoretical depth graced the pages of this journal, and many others, for over three decades. Much of that work remains highly influential in our current understanding of the control of human attention, which stands as a testament to his legacy.

Many readers will also remember the mark that Steve left on our discipline with his example. For all of his accomplishments, Steve was legendary for his gentle humility, which managed to make his presence all the more towering and awe-inspiring. He balanced a cold intellectual seriousness with a lively passion for science and life that was reflective of the theoretical balanced he maintained in his research: it all came together in a way that seemed natural and intuitive.

One of the most impressive qualities about Steve, which can be easier to miss, is his commitment to mentorship. The

Brian A. Anderson

brian.anderson@tamu.edu

1 Texas A\&M University, 4235 TAMU, College

Station, TX 77843-4235, USA

number and quality of individuals that Steve mentored to successful positions in academia and industrial research is striking, even if one does not consider the fact that he tended towards a smaller-sized lab by today's standards. One needs only glance at the editorial team for this special issue, which is, by no means, a comprehensive list to get a sense of this accomplishment. Steve was passionate about mentorship and was known to shed a tear or two when he spoke of how proud he was of his team. One of the most enduring qualities of Steve's legacy is the generation of scientists that carry on his tradition and the tradition he inherited from his own mentors (some of whom also comprise the editorial team). We are all representatives of Steve's academic family.

This special issue serves as a celebration and a remembrance of the enduring impact of Steven Yantis on our field and discipline. Fittingly, you will find a broad range of perspectives in the control of human attention: from the influence of physical salience, goal relevance, reward history, selection history, and their interaction; from the role of attention in perception to working memory; and new takes on classical experimental paradigms, the development of novel experimental paradigms, and integrative theoretical reviews. Steve's influence can be plainly seen throughout these fine contributions.

I will leave you with some remembrances from the editorial team, members of Steve's academic family who were graced with the opportunity to work alongside him. These remembrances provide a richer context for who he was as a scientist and as a person, a small piece of the story behind the life and contributions we recognize with this special issue:

The sight of Steve humbly working in his office from day to day offered me a window into what a true scholar is like-respectfully rigorous. To me, Steve did not talk a lot because he talked like he wrote. He chose his words 
as carefully as he chose experimental conditions. In contrast to his cold razor-sharp mind, Steve was also a warm caring person: he always made sure that I would have a place to go for Thanksgiving dinner.

$\sim$ Yu-Chin Chiu

Perhaps what I have learned most about from Steve is clarity. Steve was an incredibly precise thinker and it translated to clear ideas, presentations, and manuscripts. Striving for Steve's clarity has shaped my approach to science. To this day, when I have written a draft of a manuscript, I channel Steve during the editing process. What it means is that I take a paragraph and I mercilessly trim away everything that does not directly contribute to the point I am trying to make. I strive to think and write like Steve, and I suspect that I will continue channeling him for as long as I am in the field.

$\sim$ Sarah Shomstein

Steve Yantis was the sort of doctoral advisor we all strive to be: a true mentor to his students. As a graduate student of his I learned a multitude of mentoring skills, but two in particular have stayed with me. First, Steve endlessly searched for teachable moments, never letting an opportunity pass him by to educate his students. Second, Steve always checked his ego at the door; his broad scientific stature never prevented him from taking extra time with undergraduates or offering to help with mundane tasks around the lab. I think of these virtues at least once a week and in this way Steve continues on as a mentor of mine. $\sim$ Adam Greenberg

Steve had many qualities that made him an invaluable friend and colleague. Two, in particular, always stood out for me. He was extremely creative, as one can readily see from the broad range of topics he addressed in novel ways in his research. He also had extremely good judgment. This was something I relied on heavily during the whole time he was at Johns Hopkins. This judgment manifested itself in science, in departmental affairs, and in interpersonal relations. He is sorely missed.

$\sim$ Howard Egeth

Steve Yantis taught me that "I don't know,"- or as he would put it, "It's not clear to me,"- - is not a failure, but is the beginning of learning. His humility, without a discernible drop of arrogance, kept him open to new ideas, questions, and solutions. Steve showed us by his example that a good scientist and a smart person seeks out learning and discovery that cannot happen without first becoming aware of gaps in knowledge - one's own and that of the world at large.

$\sim$ Benjamin Tamber-Rosenau
Steve showed me how to be a mentor and run a lab, and I often hear his voice when interacting with my own trainees. One of the many lessons that made an impression on me was his ability to build great teams. Steve knew how to foster people's intellectual strengths, and encouraged collaborations that lead to high-impact, and creative science. During my time in the lab, he planted seeds of mutual curiosity that propelled many of our careers while thoroughly enjoying the process. Beyond imparting his great scientific instincts and leadership, one thing that he particularly impressed on me was his ability to see his scientific colleagues and trainees not just as researchers, but also as parents, family members, and members of the community. When I first interviewed for a post-doc with Steve, I was strongly advised not to mention that my wife and I were expecting our second child. When I got to his office, and saw the prideful pictures of his daughters, we talked about our family before science, and I comfortably discussed my situation. Throughout my years working with him, his concern for my career was always viewed holistically with family in mind, and this mirrored his own life. He taught me that family and career do not have to be sacrificed for one another, and this lesson of balance is one of his many gifts to me.

$\sim$ Michael Esterman

Steve represented everything a student could want in an advisor: a pioneer in the field, a patient listener, and a proud advocate of his students' work. Whether it was a pat on the back following a presentation, or a strong handshake and a big smile following completion of a qualifying exam, it felt good to know that Steve was always in my corner. In all things, Steve remained respectful, compassionate, and humble. He taught me that a sharp intellect does not need to come at the cost of humility and I will forever be grateful to have been his student.

$\sim$ Anthony Sali

I was Steve's first advisor when he started graduate school at Michigan, and I worked with him for years afterward. Steve was a scientist of great insight about matters having to do with perception, broadly conceived, and he managed to take these insights and turn them into scientific discoveries with very broad impact. I don't flatter myself by thinking that I had much to do with Steve's many accomplishments; I am just thankful that I had the opportunity to witness them.

$\sim$ John Jonides

Steve had just started to use fMRI when I started my post-doc with him. As one would expect from a great 
cognitive psychologist, Steve ensured all aspects of experimental design, stimulus development, data analysis, and interpretation were flawless. When Steve saw new brain activation results he was like a kid in a candy store, but he always conducted world-class cognitive analysis. Steve was a good person, a genius, a wonderful advisor, and a model scientist who had a major impact on the way in which I conduct science. I think of him often. $\sim$ Scott Slotnick

Steve is one of the most intelligent and kindest people I know, perhaps a somewhat rare combination of qualities. I was so fortunate to be able to work with and learn from Steve, even though my stint in the Yantis lab was relatively brief. Steve showed me how to tackle scientific questions with ingenuity and rigor, which I will forever strive to do in my own work.

$\sim$ Taosheng Liu

Steve had a reverence for the beauty of knowledge and truth that is difficult to describe. His love for the arts was obvious, and this was plainly reflected in his work. Every brush stroke was made with a purpose, every note felt inevitable. There was a sense of purity and majesty to his craft that was absolutely awe-inspiring. I will never see an elegant experiment or compelling data in the same way that I did before I knew Steve. He tuned my senses like only a Master can. Some of my most treasured memories are of composing science with my mentor.

$\sim$ Brian Anderson

As a graduate student, I occasionally had the opportunity to hear Steve share his personal perspective on his life and career. In one such conversation, his eyes lit up as he explained that his choice to become a scientist was guided by his conviction that it would bring a kind of immortality. He went on to explain that among all of the activities we can engage in during our brief time on Earth, the process of discovering and sharing knowledge has potentially the most lasting positive impact on humanity. My memory of this conversation brought some comfort around the time of his passing; we are no longer privileged to see Steve in our daily lives, but his brilliant and groundbreaking work as a scientist has indeed secured his immortality.

$\sim$ Andrew Leber 